'Department of Bioethics, The Clinical Center, National Institutes of Health, United States. ${ }^{2}$ Departamento de Bioética y Humanidades Médicas, Facultad de Medicina, Universidad de Chile. Santiago, Chile.

Funding: This work was partly supported by NIH intramural funds. The content is solely the responsibility of the author and does not represent the position of the US National Institutes of Health.

Recibido el 23 de julio de 2020 aceptado el 7 de diciembre de 2020.

Correspondencia a: Dr. Bernardo Aguilera Departamento de Bioética y Humanidades Médicas, Facultad de Medicina, Universidad de Chile. Santiago, Chile. bedobardo@gmail.com

\section{Trends in clinical trials performed in Chile}

\author{
BERNARDO AGUILERA ${ }^{1,2}$
}

\begin{abstract}
Background: An increasingly large proportion of clinical trials is being conducted at non-traditional geographic regions such as Latin America. However, concerns have been raised that hosting countries may lack adequate research regulations and that clinical trials may not address local health needs. In this context, Chile has been hosting a relatively large proportion of clinical trials and has introduced new regulatory protections. Aim: To study trends and characteristics of clinical trials in Chile, including the effects of regulatory protections and whether clinical trials are aligned with the local burden of diseases. Material and Methods: Data from clinical trials on pharmaceutical products registered over the last decade in Chile's Institute of Public Health was reviewed. Clinical trials were analyzed according to sponsorship, phase, disease studied, and whether distribution of trials according to diseases was aligned with the local burden of diseases measured in disability-adjusted life years. Results: Most of the 876 clinical trials analyzed were funded by external pharmaceutical companies and corresponded to late-phase trials. The most commonly studied disease groups were neoplasms, musculoskeletal disorders, other noncommunicable diseases, chronic respiratory diseases, diabetes and kidney diseases, neurological disorders, and circulatory diseases. The distribution of clinical trials was partially aligned with the distribution of major causes of disease burden. The introduction of new regulatory protections was followed by changes in the number of trials studying certain disease groups associated with a high burden. Conclusions: Clinical trials conducted in Chile over the last decade are largely funded by external pharmaceutical companies. Their distribution is partially aligned with local disease burden. The introduction of regulatory protections was followed by changes in the distribution of diseases studied.
\end{abstract}

(Rev Med Chile 2021; 149: 110-118)

Key words: Chile; Clinical Trial; Ethics, Research.

\section{Tendencias en ensayos clínicos realizados en Chile}

Antecedentes: Una proporción cada vez mayor de ensayos clínicos se realiza en regiones geográficas no tradicionales, como América Latina. Sin embargo, existe preocupación de que los países anfitriones no cuenten con una adecuada regulación para la investigación y que los ensayos clínicos no aborden las necesidades de salud locales. En este contexto, Chile ha albergado una proporción relativamente grande de ensayos clínicos y ha introducido nuevas protecciones 
regulatorias. Objetivo: Estudiar las tendencias y características de ensayos clínicos realizados en Chile. Conocer el efecto de protecciones regulatorias y saber si los ensayos clínicos están alineados con la carga de enfermedad del país. Material y Métodos: Se revisó la información acerca de ensayos clínicos registrados en Chile en el Instituto de Salud Pública. Estos se analizaron según patrocinio, fase, enfermedad estudiada y si la distribución de los ensayos tenía relación con la carga de enfermedad del país, medida como años de vida ajustados por discapacidad. Resultados: Se revisaron 876 ensayos clínicos. La mayoría estaban financiados por compañias farmacéuticas extranjeras y correspondian a ensayos de fases tardías. Las principales enfermedades estudiadas fueron tumores, enfermedades músculo esqueléticas, otras enfermedades no comunicables, enfermedades respiratorias crónicas, diabetes y enfermedades renales, problemas neurológicos y enfermedades cardiovasculares. La distribución de ensayos clínicos estaba parcialmente alineada con la carga de enfermedad. A las nuevas protecciones regulatorias les siguieron cambios en el número de ensayos que estudian enfermedades con alta carga. Conclusiones: Los ensayos clínicos efectuados en Chile son mayoritariamente financiados por compañias farmacéuticas extranjeras. Su distribución está parcialmente alienada con la carga de enfermedad del país. La introducción de protecciones regulatorias se asoció a un cambio en la distribución de las enfermedades estudiadas.

Palabras clave: Chile; Ensayo Clínico; Ética en Investigación.

T he global landscape of clinical research has changed in the last two decades, with increasing numbers of clinical trials (CTs) shifting to non-traditional geographic regions, especially towards so-called "emerging economies" in Latin America, Eastern Europe, and $\mathrm{Asia}^{1-3}$. In this context, Chile stands out as the country with the highest number of CTs per million population in Latin America ${ }^{4}$.

The globalization of CTs is often seen as an opportunity to shift research investment towards developing countries and bridge the global gap in research that has traditionally focused on the health priorities of high-income, developed countries $^{5}$. However, externally sponsored CTs have also been accused of taking unfair advantage of inadequate research regulations and oversight in developing countries ${ }^{6}$. As a result, many countries in the region have introduced new regulatory protections ${ }^{7,8}$. Again, Chile is a good example: In 2012 Law $20.584^{9}$ prohibited research with subjects who are unable to provide informed consent due to cognitive impairment, and in 2015, Law $20.850^{10}$ introduced stringent regulatory protections concerning compensation for research injuries and post-trial access to research treatments.
However, even well-intended regulatory protections can have unwanted consequences for the countries that promulgate them. Requirements that are more strict than the provisions of international ethical guidelines, or contain vague formulations and leave procedures unclear, can lead sponsors to conduct their CTs in countries with more convenient regulations ${ }^{11}$. In Chile, the introduction of Law 20.850 has indeed been followed by a $20 \%$ decline in the number of CTs registered in the country ${ }^{12}$. However, little is known about the characteristics of CTs conducted in Chile.

To investigate this issue, this article reviews data from registered CTs on pharmaceutical products in Chile over the last decade and characterizes them with respect to phase, sponsorship and diseases studied. To evaluate the extent to which CTs address local health needs, the proportion of CTs targeting each disease group is compared with the burden of disease attributable to that group in Chile. This investigation can shed light on how international research is being conducted in Chile, the effects of new regulatory protections, and how responsive the research is to local health needs and priorities. 


\section{Material and Methods}

In this study, I examined data on 876 CTs registered in Chile from 2010-2019, obtained through a freedom of information request to the Chilean Institute of Public Health (Instituto de Salud Pública or ISP). Sponsors are legally required to register all CTs on pharmaceutical products that have not been previously approved, or approved for a different application, by this regulatory agency ${ }^{13}$. The average time to obtain a response from the ISP was 15 days and included the title, phase, and sponsor of CTs registered on each year. To evaluate the effects of Law 20.584 the data was also analyzed considering pre- (20102012) and post- (2013-2015) enactment periods. Similarly, for Law 20.850 the data was analyzed in pre- (2010-2015) and post- (2016-2019) enactment periods.

To assess whether the conditions studied by CTs were aligned with the burden of disease in Chile, the local burden was measured in disability-adjusted life years (DALYs), a measure that represents the number of years lost due to illness, disability, or premature death. The estimate of DALYs for Chile was based on the Global Burden of Diseases 2017 Study $^{14}$. Following Atal et al. ${ }^{15}$, I considered that there was a research gap for a disease group when the proportion of CTs corresponding to that group (registered over the observed period) was less than $50 \%$ of the proportional burden of disease attributable to that group. For example, if in Chile $14 \%$ of the burden of disease corresponds to neoplasms and the proportion of trials corresponding to that disease group is less than $7 \%$, then there is a research gap. A partial research gap was identified when the proportion of CTs relative to the local disease burden fell between $50 \%$ and $75 \%$. When that proportion was higher than $75 \%$, research was considered to be aligned with the local disease burden.

The classification of disease groups was also based on the Global Burden of Diseases 2017 Study, which classified diseases into 22 groups at Level 2 of aggregation ${ }^{16}$. When more specificity was needed, disease groups were also broken down into more specific disease categories at Level 3 of aggregation. For example, the Level 2 group neoplasms maps onto 46 different cancer categories at Level 3. Finally, the classification of each trial was performed based on the study title as provided by the ISP. When the title suggested the study of more than one condition, the trial was classified based on the primary disease under study.

\section{Results}

\section{Trends in trial sponsorship 2010-2019}

Over the studied period, $96.5 \%$ of CTs on drugs in Chile have been sponsored by external pharmaceutical companies or research organizations. Local pharmaceutical companies sponsored $1.1 \%$ of CTs, whereas $2.4 \%$ of CTs were funded by non-profit institutions: local universities $(0.5 \%)$, external universities $(0.6 \%)$, local non-profit institutions $(0.5 \%)$, and external non-profit institutions $(0.9 \%)$. This overall distribution has remained stable throughout the studied time frame.

Among external pharmaceutical companies sponsoring CTs in Chile, 10 companies have sponsored $50 \%$ of CTs. Bristol-Myers, Sanofi-Aventis, GlaxoSmithKline, and AstraZeneca are among the top 5 sponsors, with Merck SD taking the lead with $9 \%$ of all CTs (Table 1). Sponsorship for the remaining $50 \%$ of CTs is diverse and includes the participation of 170 pharmaceutical companies and two Contract Research Organizations (CROs), which provide research services for large pharmaceutical companies.

\section{Clinical trials by phase and disease groups}

Over the studied period, $4 \%$ of CTs were phase $1,23 \%$ phase $2,68 \%$ phase 3 , and $5 \%$ phase 4 (Figure 1). Across time, the proportion of CTs has remained almost constant for phase 2 and phase 3 ; however, after 2015, there has been an overall increase in the propotion of phase 1 trials (3\% to $7 \%)$ and a decrease in the proportion of phase 4 trials $(6 \%$ to $3 \%)$.

With respect to the distribution of CTs by disease group (at Level 2 of aggregation), the most studied diseases correspond to neoplasms (26\%), musculoskeletal disorders (12\%), other nonconmmunicable diseases (11\%), chronic respiratory diseases (10\%), diabetes and kidney diseases (6\%), neurological disorders (6\%), and cardiovascular and circulatory diseases (6\%). Seven disease groups were each studied in a proportion between $1 \%$ and $4 \%$ of CTs. Of the remaining nine disease groups, each of them was studied by less than $1 \%$ of CTs (Table 2). 
Table 1. Number of clinical trials registered in the Chilean Institute of Public Health (ISP) between 2010 and 2019 that were funded by the ten most common sponsors

\begin{tabular}{|c|c|c|c|c|c|c|c|c|c|c|c|}
\hline & 2010 & 2011 & 2012 & 2013 & 2014 & 2015 & 2016 & 2017 & 2018 & 2019 & Total (\%) \\
\hline Merck SD & 10 & 7 & 9 & 10 & 5 & 8 & 7 & 8 & 8 & 11 & $83(9 \%)$ \\
\hline Bristol-Myers Squibb & 2 & 2 & 6 & 3 & 3 & 7 & 6 & 5 & 10 & 8 & $52(6 \%)$ \\
\hline Sanofi-Aventis & 7 & 4 & 6 & 7 & 5 & 5 & 7 & 2 & 6 & 2 & $51 \quad(6 \%)$ \\
\hline GlaxoSmithKline & 6 & 7 & 15 & 5 & 9 & 4 & 0 & 0 & 0 & 0 & $46 \quad(5 \%)$ \\
\hline AstraZeneca & 7 & 0 & 5 & 5 & 8 & 6 & 5 & 2 & 1 & 6 & $45 \quad(5 \%)$ \\
\hline Pfizer & 6 & 4 & 5 & 8 & 4 & 2 & 3 & 3 & 5 & 4 & $44 \quad(5 \%)$ \\
\hline Novartis & 2 & 4 & 1 & 2 & 1 & 4 & 4 & 4 & 5 & 8 & $35(4 \%)$ \\
\hline Roche & 0 & 4 & 6 & 1 & 3 & 5 & 1 & 4 & 5 & 2 & 31 (4\%) \\
\hline Abbvie & 0 & 0 & 1 & 4 & 3 & 1 & 3 & 3 & 10 & 3 & $28(3 \%)$ \\
\hline Boehringer Ingelheim & 4 & 3 & 3 & 3 & 6 & 2 & 2 & 3 & 0 & 0 & $26(3 \%)$ \\
\hline Other sponsors & 55 & 60 & 50 & 39 & 47 & 47 & 45 & 34 & 27 & 31 & 435 (50\%) \\
\hline
\end{tabular}

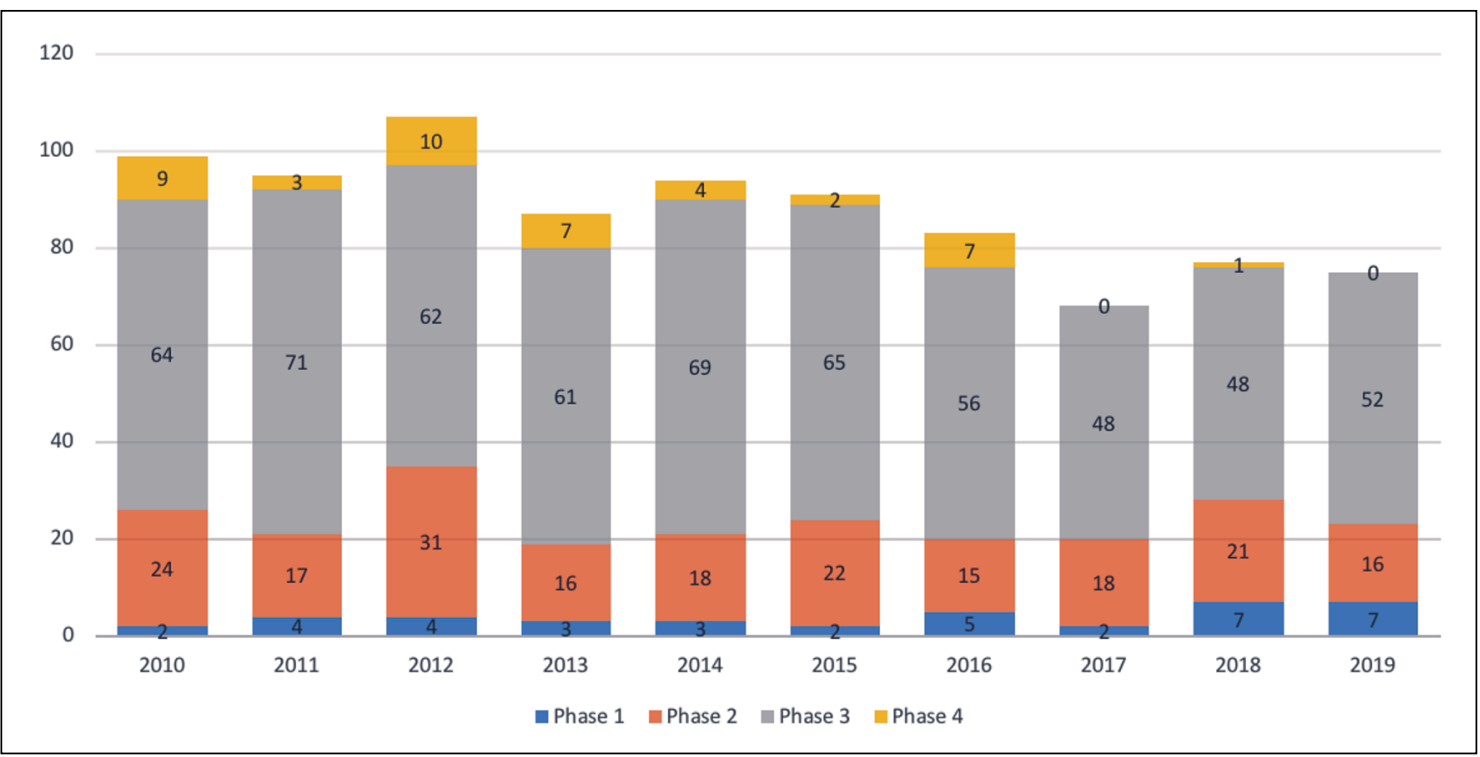

Figure 1. Total number of clinical trials registered in the Chilean Institute of Public Health (ISP) and their respective phases between 2010 and 2019 ( $n=876$ ). Two trials from 2011 and one from 2017 were excluded because they were not reported as corresponding to phases 1-4.

\section{Clinical trials by disease groups after the enactment of Laws 20.584 and 20.850}

In the three years following the enactment of Law 20.584 in 2012 there was a decrease in the proportion of CTs studying other noncommunicable diseases (15\% to $10 \%)$, neurological disorders ( $9 \%$ to $6 \%)$ and mental disorders (4\% to $1 \%)$. On the other hand, during the same time period there was an increase in the proportion of CTs studying five disease groups, notably chronic respiratory diseases (10\% to $13 \%)$, respiratory infections and tuberculosis $(2 \%$ to $5 \%)$ and neoplasms ( $19 \%$ to $21 \%)$. The remaining disease groups stayed constant or their proportion varied less than $2 \%$ between pre- and post-law periods (Figure 2).

With respect to Law 20.850, after it was enacted in 2015 there was a increase in the proportion of CTs studying neoplasms (20\% to $38 \%$ ), digestive 
Table 2. Proportion of clinical trials registered in the Chilean Institute of Public Health (ISP) between 2010 and 2019 that study each of the 22 groups of diseases at Level 3 of aggregation (left column) and proportion of the local disease burden corresponding to each disease group obtained from the Global Burden of Diseases 2017 Study ${ }^{14}$ (right column). Disease groups for which there is a research gap are in yellow, those with partial gap in blue, and those aligned with the research effort are in green. A line connects the same disease groups between the two columns

\begin{tabular}{|c|c|c|c|}
\hline \multicolumn{2}{|r|}{$\begin{array}{l}\text { Proportion of registered clinical } \\
\text { trials studing each group in Chile }\end{array}$} & \multicolumn{2}{|c|}{$\begin{array}{l}\text { Proportion of disease burden } \\
\text { attributable to each group in Chile }\end{array}$} \\
\hline $26 \%$ & Neoplasms & Neoplasms & $14 \%$ \\
\hline $12 \%$ & Musculoskeletal disorders & Musculoskeletal disorders & $13 \%$ \\
\hline $11 \%$ & Other nonconmmunicable D. & Cardiovascular and C. diseases & $12 \%$ \\
\hline $10 \%$ & Chronic respiratory diseases & Mental disorders & $8 \%$ \\
\hline $6 \%$ & Diabetes and kidney D. & Neurological disorders & $6 \%$ \\
\hline $6 \%$ & Neurological disorders & Diabetes and kidney D. & $6 \%$ \\
\hline $6 \%$ & Cardiovascular and C. diseases & Other nonconmmunicable D. & $5 \%$ \\
\hline $4 \%$ & Respiratory infections and TB. & Digestive diseases & $5 \%$ \\
\hline $4 \%$ & Digestive diseases & Unintentional injuries & $5 \%$ \\
\hline $3 \%$ & HIV/AIDS and STIs & Chronic respiratory diseases & $4 \%$ \\
\hline $3 \%$ & Other infectious diseases & Self-harm and Violence & $3 \%$ \\
\hline $3 \%$ & Mental disorders & Sense organ diseases & $3 \%$ \\
\hline $3 \%$ & Skin and subcutaneous D. & Maternal and neonatal D. & $3 \%$ \\
\hline $2 \%$ & Sense organ diseases & Transport injuries & $3 \%$ \\
\hline $1 \%$ & Maternal and neonatal D. & Skin and subcutaneous D. & $3 \%$ \\
\hline $1 \%$ & Enteric infections & Substance use & $2 \%$ \\
\hline $0 \%$ & Substance use & Respiratory infections and TB. & $2 \%$ \\
\hline $0 \%$ & NTDs and malaria & HIV/AIDS and STIs & $1 \%$ \\
\hline $0 \%$ & Nutritional deficiencies & Nutritional deficiencies & $1 \%$ \\
\hline $0 \%$ & Unintentional injuries & Enteric infections & $1 \%$ \\
\hline $0 \%$ & Self-harm and Violence & Other infectious diseases & $0 \%$ \\
\hline $0 \%$ & Transport injuries & NTDs and malaria & $0 \%$ \\
\hline
\end{tabular}

diseases (2\% to $7 \%)$, respiratory infections and tuberculosis (3\% to $4 \%)$, sense organ diseases ( $1 \%$ to $2 \%)$, and maternal and neonatal disorders (1\% to $2 \%$ ). By contrast, the proportion of CTs studying seven disease groups has decreased, notably other noncommunicable diseases (12\% to 9\%) and chronic respiratory diseases ( $12 \%$ to $7 \%$ ). The remaining disease groups have stayed constant between pre- and post-law periods (Figure 2).

\section{Alignment between CTs and the burden of disease in Chile}

When viewed at Level 2 of aggregation, 11 of the 22 disease groups' local burden of disease is aligned with the research effort (measured as the respective number of CTs registered between 2010 and 2019). They include the two disease groups with the highest burden of disease in Chile (neoplasms and musculoskeletal disorders). In contrast, 


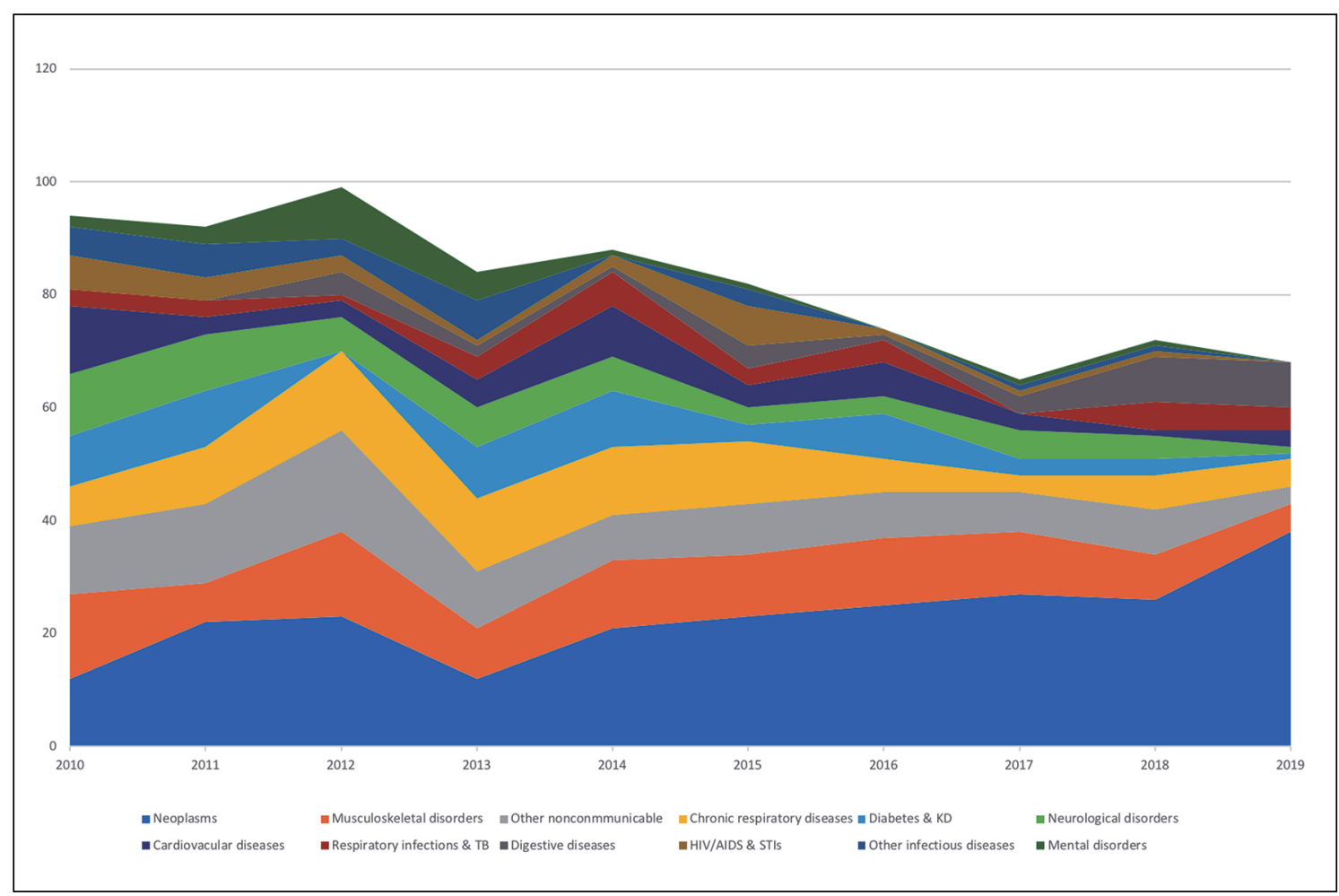

Figure 2. Number of clinical trials registered in the the Chilean Institute of Public Health (ISP) between 2010 and 2019 corresponding to the twelve disease categories that have more trials studying them ( $93 \%$ of total clinical trials).

in 9 disease groups the local burden of disease is misaligned with the research effort (i.e. there is a research gap). They include the third and fourth main causes of disease burden in Chile (cardiovascular and circulatory diseases and mental disorders). Finally, there is a partial alignment between research effort and disease burden for two disease groups (digestive diseases and sense organ diseases) (Table 2).

To examine how much research effort is placed on more specific diseases associated with a high disease burden in Chile, a similar analysis was carried based on the ten most common causes of DALYs in Chile considered at Level 3 of aggregation. These are low back pain, ischemic heart disease, stroke, diabetes, cirrhosis, neonatal disorders, depressive disorders, headache disorders, road injuries, and anxiety disorders. Altogether, these disease categories correspond to $37 \%$ of the Chilean burden of disease. However, just $16 \%$ of CTs registered between 2010 and 2019 address one of them.

\section{Discussion}

The globalization of clinical research over the last two decades has seen a migration of CTs to emerging economies with a high proportion of industry-sponsored research. Chile provides a good example of this phenomenon, as well as of attemps to protect research participants through legal requirements. The present study provides the first analysis of trends in CTs over an extended period in a Latin American country, including trial sponsorship, diseases studied, and the effects of new legal protections.

The vast majority of CTs in Chile are sponsored by external pharmaceutical companies or CROs and $70 \%$ correspond to late-phase or post marketing studies. This is consistent with data about CTs conducted in other emerging regions $s^{17,18,19}$. In contrast, a marginal amount of CTs in Chile are sponsored by local pharmaceutical companies, universities, or other non-profit institutions. This may be due to several factors, including the high 
costs of conducting CTs, and insufficient research training and infrastructure ${ }^{20,21}$. Even though progress has been made in the development of funding instruments for basic and applied research in Chile, public support for the long and costly clinical trial process remains limited ${ }^{22,23}$. These factors can also help explain the low proportion of phase 1 and 2 CTs conducted in Chile, since these early-phase CTs are more demanding in terms of the research capacity and infrastructure required.

For private sponsors, the ten largest global pharmaceutical companies (by market share ${ }^{24}$ have a share in the sponsorship of CTs conducted in Chile. Five of those companies figure among the top ten sponsors in the country (Table 1). However, there is a strikingly high number of different private for-profit entities $(n=182)$, resulting in most of them $(n=143)$ being sponsors of less than three CTs in Chile over the studied period. These are mostly small and medium-sized pharmaceutical companies, which have been described as "the growth engine of the pharmaceutical industry" 25 .

The overall distribution of disease groups studied since 2010 shows that the majority of CTs registered in Chile (59\%) are concentrated on four groups: neoplasms, musculoskeletal disorders, other noncommunicable diseases and chronic respiratory diseases (Figure 2). In contrast, the nine disease groups that are less studied by CTs comprise less than $5 \%$ of CTs registered in the country. The overall research effort appears to be partially aligned with the burden of disease in Chile. Even though half of the 22 Level 2 disease groups show a good alignment between CTs studying them and the disease burden, some diseases with a high local burden appear to be understudied (e.g. cardiovascular and circulatory diseases and mental disorders). This idea is confirmed by the more specific analysis of disease groups at Level 3 of aggregation, which shows a research gap for the ten most common causes of DALYs in Chile. Therefore, the partial alignment between research effort and disease burden in Chile may be less than what was suggested by the analysis of diseases at Level 2 of aggregation.

Law 20.584 has been followed by a sharp decline in CTs targeting neurological disorders and mental disorders. Since there has been no global downward trend in CTs studying those disease groups $^{26}$, this decline may be explained by the fact that law 20.584 prohibited research with subjects who are unable to provide informed consent due to cognitive impairment. This is cause of concern since neurological and mental disorders are among those with the highest burden in Chile. As for Law 20.850 , the reduction in the overall number of CTs after its enactment has been accompanied by an increase in the proportion of CTs dealing with certain disease groups, notably CTs studying neoplasms which have more than doubled after 2015. This may be explained by the fact that oncology is the area with the largest proportion of clinical development spending worldwide ${ }^{27}$. Research on neoplasms in Chile is worthwhile since this disease group causes important social and economic burdens, which can be expected to increase given the country's rapidly aging population ${ }^{28}$. Meanwhile, the proportion of CTs studying certain disease groups has declined after Law 20.850. The most significant reductions (to half or less of their prelaw percentage) have been in cardiovascular and circulatory diseases, mental disorders, and neurological disorders. This is concerning since these disease groups are among the top five groups with the highest disease burden in Chile.

There are some limitations to the present research. CTs included in this study are just those registered in the ISP and therefore focus on testing pharmaceutical products. Unfortunately, registration of non-pharmaceutical CTs is not mandatory in Chile and there is no reliable registry of them. This omission may lead to an underestimation of the local research effort, in particular concerning disease groups which are less likely to be studied through pharmacological interventions (e.g. transport injuries). In addition, given that the absolute number of CTs conducted in Chile is relatively low, the variations observed after the enactment of Laws 20.584 and 20.850 may not justify categorical statements.

\section{Conclusions}

Clinical trials conducted in Chile over the last decade are largely funded by external pharmaceutical companies, with marginal participation of local private or public sponsors. The majority of CTs correspond to late-phase studies focusing on four disease groups. The introduction of new regulatory protections has been followed by a decline in CTs studying certain disease groups associated 
with a high disease burden in Chile, which is cause of concern. At the same time, CTs studying other disease groups associated with high local buden (especially neoplasms) have increased in recent years, which may be explained by global trends in industry reseearch. But since the absolute number of trials per year has decreased after the regulatory protections, it is plausible to hypothesize that the regulations have had a disincentivizing effect on at least some areas of research.

Overall, CTs in Chile are partially aligned with the local burden of disease. When disease groups are broken down into more specific categories, diseases carrying the highest local disease burden appear to be associated with a relatively low research effort. This suggests that the decision of which diseases are targeted by CTs in Chile is based on commercial interests and not on what are the most pressing health needs of the population (Cf. 29). Regulations and policies that promote collaborative partnerships between external sponsors and local authorities, as well as provide more funding and support for local researchers, may pave the way towards making CTs more responsive to the local health priorities and more likely to yield benefits such as improving local healthcare and research capabilities.

Acknowledgements: Thanks to Talia Bernhard, David DeGrazia, Joseph Millum, Annette Rid, Holly Taylor, Verónica Vargas and two anonymous referees for helpful comments on earlier versions of the manuscript.

\section{References}

1. Drain PK, Robine M, Holmes KK, Bassett IV. Global migration of clinical trials in the era of trial registration. Nat Rev Drug Discov. 2014; 13 (3): 166.

2. Thiers FA, Sinskey AJ, Berndt ER. Trends in the globalization of clinical trials. Nat Rev Drug Discov. 2008; 7: 13-4.

3. Jeong S, Sohn M, Kim JH, Ko M, Seo HW, Song YK, et al. Current globalization of drug interventional clinical trials: characteristics and associated factors, 2011-2013. Trials. 2017; 18 (1): 288.

4. Pugatch Consilium. The biopharmaceutical competitiveness \& investment (BCI) survey 2017, Latin America special report, 2017.

5. Haeussler C, Rake B. The changing geography of clinical research: a critical analysis of its drivers. Industrial and Corporate Change. 2017; 26 (2): 285-310.

6. MacMahon S, Perkovic V, Patel A. Industry-sponsored clinical trials in emerging markets: time to review the terms of engagement. JAMA. 2013; 310 (9): 907-8.

7. Homedes N, Ugalde A. Clinical Trials in Latin America: Where Ethics and Business Clash. Cham: Springer; 2014.

8. Saenz C, Heitman E, Luna F, Litewka S, Goodman KW, Macklin R. Twelve Years of Fogarty-Funded Bioethics Training in Latin America and the Caribbean: Achievements and Challenges. J Empir Res Hum Res. 2014; 9 (2): 80-91.

9. Law No. 20.584/2012 (Chile). Available: http://bcn. cl/1uw7l [Accessed 27 Jun 2020].

10. Law No. 20.850/2015 (Chile). Available: http://bcn. cl/1v7lo [Accessed 27 Jun 2020].

11. Wertheimer A. The ethics of promulgating principles of research ethics: the problem of diversion effects. Journal of Law and the Biosciences. 2015; 2 (1): 2-32.

12. Aguilera B, DeGrazia D, Rid A. Regulating international clinical research: an ethical framework for policy-makers. BMJ Global Health. 2020; 5 (5): e002287.

13. Exempt Resolution 2263 (Chile). Modifica Resolución no. 403 Exenta, de 5 de febrero de 2015, que aprueba la "Guía para la autorización y control del uso de productos farmacéuticos en investigación científica”. Available: https://www.leychile.cl/Navegar?idNorma=1080011\&idVersion=2017-01-07 [Accessed 27 Jun 2020].

14. Institute for Health Metrics and Evaluation (IHME). GBD 2017 Compare Viz Hub. Chile profile. Seattle, WA: IHME, University of Washington, 2018. Available: http://ihmeuw.org/4r9o. [Accessed 27 Jun 2020]

15. Atal I, Trinquart L, Ravaud P, Porcher R. A mapping of 115,000 randomized trials revealed a mismatch between research effort and health needs in non-high-income regions. Journal of clinical epidemiology. 2018 Jun 1; 98: 123-32.

16. Institute for Health Metrics and Evaluation (IHME). About GBD 2017. FAQ. Is there a full list of GBD causes?. Available from http://www.healthdata.org/gbd/faq [Accessed 27 Jun 2020].

17. Murthy S, Mandl KD, Bourgeois FT. Industry-sponsored clinical research outside high-income countries: an empirical analysis of registered clinical trials from 2006 to 2013. Health Res Policy Syst. 2015; 13 (1): 28.

18. Binkowitz B, Ibia E. Multiregional clinical trials: An introduction from an industry perspective. Drug Information Journal. 2011; 45 (5): 569-73.

19. Atal I, Trinquart L, Porcher R, Ravaud P. Differential globalization of industry-and non-industry-sponsored clinical trials. PloS One. 2015; 10 (12): e0145122. 
20. Gyawali B, Bouche G, Crisp N, André N. Challenges and opportunities for cancer clinical trials in low-and middle-income countries. Nat Cancer. 2020; 1 (2): 142-5.

21. Atenas TL, Sabbagh FB, Grau MF, Alvarez CM, Leal JR. Realidad de la Investigación en Salud en Chile: participación de los Médicos en el Fondo Nacional de Investigación (FONIS) en la última década. ARS MEDICA Revista de Ciencias Médicas. 2017; 42 (2): 76-80.

22. Boisier ME, Cevallos RA. Instrumentos de fomento para la investigación en Chile: historia reciente, estado actual y desafíos. Revista Médica Clínica Las Condes. 2019; 30 (1): 19-28.

23. Benedetti V, Echeverria G, Riquelme I. Biomedical research in Latin America: we can do more. The Lancet. 2016; 387 (10022): 941.

24. Pharmaceutical Technology. The top ten pharmaceutical companies by market share in 2018 [Internet]. Pharmaceutical Technology; 2019 March 7. Available: https://www.pharmaceutical-technology.com/features/ top-pharmaceutical-companies/ [Accessed 27 Jun 2020].

25. Husain ST. Supporting the Pharma Industry Small Business Growth Engine [Internet]. Pharma’s Almanac; 2017
March 8 [cited 27 Jun 2020]. Available: https://www. pharmasalmanac.com/articles/supporting-the-pharma-industry-small-business-growth-engine [Accessed 27 Jun 2020].

26. Marshall IJ, L'Esperance V, Marshall R, Thomas J, Noel-Storr A, Soboczenski F, Nye B, Nenkova A, Wallace BC. State of the evidence: a survey of global disparities in clinical trials. Forthcoming in BMJ Global Health.

27. EvaluatePharma. World Preview 2019, Outlook to 2024. 12th edition [Internet]. Evaluate; 2019 June 04. Available from: https://www.evaluate.com/thought-leadership/ pharma/evaluatepharma-world-preview-2019-outlook-2024 [Accessed 27 Jun 2020].

28. Jiménez de la Jara J, Bastias G, Ferreccio C, Moscoso C, Sagues S, Cid C, Bronstein E, Herrera C, Nervi B, Corvalan A, Velasquez EV. A snapshot of cancer in Chile: analytical frameworks for developing a cancer policy. Biol Res. 2015; 48 (1): 1-5.

29. Adam T, Ralaidovy AH, Swaminathan S. Biomedical research; what gets funded where?. Bulletin of the World Health Organization. 2019; 97 (8): 516. 